\title{
Food habits and physical activity patterns among Palestinian adolescents: findings from the national study of Palestinian schoolchildren (HBSC-WBG2004)
}

\author{
H Al Sabbah ${ }^{1,2}$, C Vereecken $^{1}$, P Kolsteren $^{3}$, Z Abdeen $^{2, *}$ and L Maes ${ }^{1}$ \\ 'Department of Public Health, Faculty of Medicine, Ghent University, Belgium: ${ }^{2}$ Nutrition and Health Research \\ Institute, Al Quds University, PO Box 20760, Jerusalem, Palestine: ${ }^{3}$ Department of Food Safety and Food Quality, \\ Faculty of Bioscience Engineering, Ghent University, Belgium
}

Submitted 20 December 2005: Accepted 13 November 2006: First published online 22 February 2007

\begin{abstract}
Objective: To describe the food habits and physical (in)activity patterns and to investigate the relationship with sociodemographic factors among Palestinian adolescents.

Design and subjects: The Palestinian Health Behaviour in School-aged Children (HBSC) is a cross-sectional survey of grades 6, 8, 10 and 12. Students completed a modified version of the international HBSC questionnaire. A total of 8885 students were included in this analysis; 53\% were from the West Bank and 47\% from the Gaza Strip. Results: Adolescents in the West Bank consume more fruit, meat, chicken, sweets and soft drinks, but less vegetables than adolescents in Gaza $(P<0.01)$. Girls reported more daily consumption of fruit, vegetables and sweets than boys $(P<0.001)$, and less consumption of soft drinks, milk, meat and chicken $(P<0.01)$. Boys were physically more active than girls $(P<0.01)$, whereas girls reported doing more homework $(P<0.001)$. Both boys and girls reported less physical activity with increasing age $(P<0.001)$. Consumption of fruit and milk was positively associated with both parents' education, while consumption of meat, chicken and soft drinks was positively associated with mother's education only. Having breakfast on schooldays was positively associated with the father's education. Physical activity and television viewing were associated with the mother's education $(P<0.01)$. The parents' level of education had no effect on vegetable consumption and dieting status.

Conclusion: This study indicated that there are problems with Palestinian adolescents' eating, dieting and physical activity. Regional, gender and parental socio-economic status differences should be taken into account in developing interventions. More detailed studies are needed with more elaborate instruments about food habits and physical activity of adolescents.
\end{abstract}

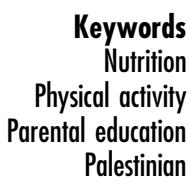

Adolescent food habits and physical activity patterns are an important concern in the present accelerated nutrition transition ${ }^{1}$. Healthy food choices combined with regular physical activity help to prevent a variety of chronic diseases such as obesity, high blood pressure, high blood cholesterol, diabetes, heart disease and certain cancers ${ }^{2-4}$. The key features of adolescents' eating patterns include snacking, skipping breakfast, dieting and adoption of specific diets ${ }^{5}$. Parents have the most influence on their child's dietary habits and physical activity patterns, and most parents make significant personal investment in their children's future. It was found that the quality of diet and physical activity among adolescents is associated with the mother's educational level and family income ${ }^{6-8}$.

Health behaviour of schoolchildren constitutes one of the most serious challenges policy-makers and professional bodies face worldwide. Health-related behaviour during adolescence has been linked to patterns of behaviour in adulthood ${ }^{2}$. The Health Behaviour in Schoolaged Children (HBSC), a World Health Organization (WHO) cross-national survey, is a unique international research study on health and health behaviour of adolescents across more than 35 countries. The study aims at understanding youth health behaviour and lifestyle in these countries?

Studying the health behaviour of Palestinian adolescents is important, since they represent about one-third of the population of the Palestinian Territories $(32 \%$ at the end of 2000) ${ }^{10}$. The West Bank and Gaza Strip are the two geographically separate entities of what is called the Palestinian Territories: West Bank covers an area of 5690 sq km with 2356810 inhabitants and the Gaza Strip is 
around $365 \mathrm{sq} \mathrm{km}$ with 1364733 people according to the Palestinian Central Bureau of Statistics. The physical separation of people and the severe restrictions on movement of people and goods have been associated with massive declines in economic access to food and consequent increases in food insecurity.

Dietary habits and the nutritional status of Palestinian pre-school children (aged 6-59 months) ${ }^{11,12}$, nonpregnant women (aged 15-49 years) ${ }^{12}$ and adults (aged 18-64years) ${ }^{13}$ have been investigated; however, data about nutrition and physical activity patterns among Palestinian schoolchildren are lacking ${ }^{14}$. In 2003/2004, the Palestinian HBSC survey was carried out for the first time in an Arab country and it is the second Palestinian national health study conducted in Palestine. The purpose of this paper is (1) to describe food habits and physical (in)activity patterns among Palestinian adolescents; and (2) to investigate the relationship between sociodemographic factors (region, gender, grades and parental level of education) and food habits and physical (in)activity patterns in Palestine in order to provide information for further related research and to direct organisations developing intervention strategies to improve the food habits and physical activity patterns of Palestinian adolescents.

\section{Subjects and methods}

The 2003/2004 Palestinian HBSC survey was approved by Al Quds University Ethical Committee and the Research Ethics Board of the Palestinian Ministry of Education. This study was based on the protocol of the 2001/2002 survey of the WHO international HBSC study?

\section{Sample selection}

A stratified random sampling strategy was employed. Within each district, samples were selected to represent distributions of schools by size, locality, gender and school type (public, United Nations Relief Work Agency or private). The distribution of the students reflected the distribution of Palestinians in grades 6, 8, 10 and 12, whose ages ranged between 12 and 18 years. Therefore, the sample of this survey was nationally representative.

The sample was drawn based on the 2003-2004 list of schools and classrooms (which included the number of students per classroom) provided by the Palestinian Ministry of Education. Adolescent schools $(n=405)$ were selected randomly throughout the two regions. All students in selected classes in grades 6, 8, 10 and 12 were eligible to participate at the time the questionnaire was distributed. There were no exclusion criteria. The total sample was 17817. After excluding 102 questionnaires which were not correctly filled in, the final number of questionnaires entered into the computer was 17715 .

\section{Instrument}

The questionnaire was developed using the WHO international HBSC questionnaire (2001-2002) including all mandatory HBSC questions ${ }^{15}$. The questionnaire was translated into the native language (Arabic) and piloted on 300 students who were selected from an adolescent school that was not included in the final sample. Changes in wording were made to clarify the meaning of certain questions; however, in order to maintain comparability with other countries, the questionnaire changes were kept to a minimum. The questionnaire contained six optional packages: half of the optional components of the questionnaire (Form A) contained optional questions on smoking, violence and injuries, and social inequalities, and the other half of the questionnaire (Form B) contained optional questions on physical activity, eating, dieting, and mental and physical health. Equal numbers of Form A and Form B were randomly distributed in each school class.

\section{Procedures}

Selected schools were informed about the survey by a letter to the school principal. All school principals agreed to participate. Completion of the survey took one class period (40-60 min). Data were collected during the second term between April and May 2004. A self-report survey questionnaire was administered in the classroom in the presence of a school psychologist and with the absence of the class teacher. Researchers followed a standardised protocol in giving instructions to students and answering questions about individual items. Student participation was voluntary; however, no student refused to cooperate in the research. Verbal and written instructions reminded students of the importance of giving honest answers, not writing their names on the questionnaire to maintain confidentiality and not talking during questionnaire completion.

\section{Measures}

Food consumption

Food and beverage consumption was measured using the following question: How many times a week do you usually eat or drink ... fruit/vegetables/sweets (candy or chocolate)/Coke or soft drinks that contain sugar/milk/ meat and chicken? The response categories were 'never', 'less than once a week', 'once a week', '2-4 days a week', '5-6 days a week', 'once a day every day' and 'every day, more than once'. Responses were categorized into: (1) less than once a day; (2) once or more a day.

\section{Breakfast during schooldays}

Students were asked how often they usually had breakfast (more than a glass of milk or fruit juice). Response categories were: '1 day', '2 days', '3 days', ' 4 days' and '5 days'. Responses were categorized into: (1) $<4$ days a week; (2) $\geq 4$ days a week. 


\section{Dieting}

Dieting status was assessed by asking: At present, are you on a diet or doing something else to lose weight? Response categories were: (1) on a diet; (2) not dieting.

\section{Physical activity}

Students were asked two questions about their physical activity status: (a) Over the past 7 days, on how many days were you physically active for a total of at least $60 \mathrm{~min}$ per day? (b) Over a typical or usual week, on how many days are you physically active for a total of at least $60 \mathrm{~min}$ per day? Response categories were: 0 days, 1, 2, etc up to 7 days. The average response $((a+b) / 2)$ from both questions was categorized into: (1) physical activity $\geq 5$ days a week; (2) physical activity $<5$ days a week.

\section{Physical inactivity}

Physical inactivity was examined by asking three questions about time usually spent during schooldays and at the weekend on television (TV) viewing, doing homework and computer use. (a) About how many hours a day do you usually watch television (including videos) in your free time? (b) About how many hours a day do you usually spend doing school homework outside of school hours? Response categories were: 'none at all', about half an hour a day, about 1 hour a day, 2, 3, 4, 5, 6, 7 or more hours a day. Mean hours for TV viewing and doing homework were derived by calculating mean hours per day from reported schooldays and weekend days and categorized into: (1) $\geq 4 \mathrm{~h}$ a day; (2) $<4$ h day. (c) About how many hours a day do you usually use a computer (for homework, programming, computer games, chats and emails, surfing and downloads)? Response categories were: 'none at all', 'less than 1 hour', ' $1-2$ hours', ' $2-3$ hours', ' 4 hours or more'. Because of the low numbers of students reporting using computers, responses were categorized into: (1) using a computer; (2) not using a computer.

\section{Parents' educational level}

This was based on adolescents' self-reports and was divided into four levels: did not graduate from high school; graduated from high school; continued studies after high school but not in university; studied in university or graduated from the university. Responses are categorized into: (1) low education - a combination of the first two categories; (2) high education - a combination of the last two categories.

\section{Statistical analysis}

Data analysis was performed using SPSS version 12. Analyses were done for boys and girls separately, as an interaction effect was found between gender and region for several outcome variables. $\chi^{2}$ tests were used to compare differences in food habits and physical activity by gender, grade and region. Logistic regression (binary logistic) was used to investigate the effect of mother's/father's level of education controlling for region, grade and gender. As no interaction effect was found between mother's/father's level of education and region, analyses were done for both regions together.

\section{Results}

In total, 8885 questionnaires (Form B) are considered in the analysis for this paper; $53 \%$ are from the West Bank and $47 \%$ from the Gaza Strip. Of the respondents, $49 \%$ were boys and 51\% girls. Of all adolescents, 45\% reported consuming vegetables, followed by sweets (35\%), fruits (31\%) soft drinks (24\%), milk (22\%), and meat and chicken (16\%) daily. About half (45\%) reported taking breakfast $\geq 4$ days a week during schooldays. Dieting was reported in $8 \%$ of the respondents and (20\%) were doing physical activity $\geq 5$ days during the past week or the usual week. The mean (standard deviation (SD)) was 2.8 (2.1) days per week. For sedentary activities, 29\% reported watching TV $\geq 4 \mathrm{~h}$ a day and $29 \%$ reported using a computer, while $18 \%$ reported doing homework $\geq 4 \mathrm{~h}$ a day (Table 1 ).

\section{Differences by region}

Table 2 shows many significant differences in food habits and physical activity among Palestinian adolescents between regions. Adolescents from the West Bank eat fruit, sweets, meat and chicken more often and drink soft drinks more often than adolescents of Gaza $(P<0.001)$ while adolescents from Gaza eat vegetables more $(P<0.01)$. Adolescents of the West Bank are more active, watch more TV and use the computer more than adolescents of Gaza $(P<0.001)$.

\section{Differences by gender and region}

In general, girls in both regions reported more daily consumption of fruit, vegetables and sweets than boys $(P<0.001)$, while their reported daily consumption of soft drinks, milk, meat and chicken was less $(P<0.01)$. Boys from the West Bank reported eating fewer vegetables

Table 1 Demographic characteristics of the study participants $(n=8885)$, Palestine, HBSC, 2004

\begin{tabular}{lcc}
\hline & $n(\%)$ & Mean age (SD) (years) \\
\hline $\begin{array}{l}\text { Gender } \\
\text { Male }\end{array}$ & $4313(49)$ & $15.1(2.3)$ \\
$\quad$ Female & $4572(51)$ & $15.0(2.3)$ \\
Region & & \\
$\quad$ West Bank & $4730(53)$ & $14.9(2.3)$ \\
$\quad$ Gaza Strip & $4155(47)$ & $15.2(2.2)$ \\
Grade & & \\
6th grade & $2225(25)$ & $12.0(0.5)$ \\
8th grade & $2291(26)$ & $14.0(0.4)$ \\
10th grade & $2210(25)$ & $16.0(0.4)$ \\
12th grade & $2159(24)$ & $18.0(0.6)$
\end{tabular}

HBSC - Health Behaviour in School-aged Children; SD - standard deviation. 
Table 2 Description (\%) of food intake and physical activity variables by region and significance of the difference, Palestine, HBSC, 2004

\begin{tabular}{|c|c|c|c|c|}
\hline & West Bank $(n=4730)$ & Gaza $(n=4155)$ & Total $(n=8885)$ & $P^{*}$ \\
\hline Fruit (daily: once or more per day) & 34 & 28 & 31 & $<0.001$ \\
\hline Vegetables (daily: once or more per day) & 43 & 47 & 45 & 0.001 \\
\hline Sweets (daily: once or more per day) & 39 & 31 & 35 & $<0.001$ \\
\hline Soft drinks (daily: once or more per day) & 29 & 17 & 24 & $<0.001$ \\
\hline Milk (daily: once or more per day) & 22 & 23 & 22 & 0.773 \\
\hline Meat and chicken (daily: once or more per day) & 19 & 12 & 16 & $<0.001$ \\
\hline Breakfast on schooldays ( $\geq 4$ days a week) & 43 & 46 & 45 & 0.028 \\
\hline On diet (dieters) & 7.3 & 8.2 & 7.7 & 0.148 \\
\hline Physical activity ( $\geq 5$ days a week) & 25 & 13 & 20 & $<0.001$ \\
\hline TV viewing ( $\geq 4 \mathrm{~h}$ a day) & 32 & 25 & 29 & $<0.001$ \\
\hline Homework ( $\geq 4 \mathrm{~h}$ a day) & 18 & 18 & 18 & 0.253 \\
\hline Using computer & 31 & 27 & 29 & $<0.001$ \\
\hline
\end{tabular}

HBSC - Health Behaviour in School-aged Children; SD - standard deviation.

${ }^{*} \mathrm{~A}$ significant difference between regions by $\chi^{2}$ test.

than boys of Gaza $(P<0.001)$, while no significant difference was found among girls between regions. More boys in Gaza were on a diet or doing something else to lose weight than boys in the West Bank; the highest percentage of dieting (17\%) was found among boys in grade 6 in Gaza. However, no significant difference was found among girls between regions regarding dieting status (Tables 3 and 4).

In both regions, boys were physically more active than girls $(P<0.01)$, whereas girls reported doing more homework $(P<0.001)$. Boys in Gaza spend more time doing homework than boys in the West Bank $(P<0.001)$, and girls in the West Bank also spend more time doing homework than girls in Gaza $(P<0.01)$. In addition, girls from the West Bank watch TV more than boys $(P<0.001)$ while no significant difference was found in Gaza between boys and girls in terms of watching TV. Boys from both regions spend equal amounts of time on the computer, whereas girls from the West Bank spend more time on it than girls from Gaza $(P<0.001)$ (Tables 3 and 4$)$.

\section{Differences by grades and region}

Several age-related differences were found in both boys and girls (Tables 3 and 4). Adolescents of the West Bank and only boys of Gaza eat less fruit with increasing age $(P<0.01)$. Boys in both regions drink less milk with increasing age $(P<0.01)$. In girls, the higher percentages reporting drinking milk were found in grade 6 in both regions. Girls of the West Bank eat less meat and chicken with increasing age $(P<0.001)$; this trend was not observed in Gaza. In girls, in both regions, a significant difference $(P<0.01)$ was found between grades in taking breakfast during the schooldays; the highest percentages were found in grade 6 (Tables 3 and 4).

Adolescents of both regions decrease their physical activity with increasing age $(P<0.001)$. Adolescents of the West Bank in grade 12 do more homework and use a computer less than adolescents in other grades. The highest percentages reporting doing homework (46\% and 31\%), and the lowest percentages reporting using computers (17\% and 19\%) were found among girls in grade 12 in both the West Bank and Gaza, respectively.

Table 3 Description (\%) of food intake and physical activity variables of boys by region and grades $6,8,10$ and 12 , and significance of the difference, Palestine, HBSC, 2004

\begin{tabular}{|c|c|c|c|c|c|c|c|c|c|c|c|c|c|}
\hline & \multicolumn{6}{|c|}{ West Bank $(n=2382)$} & \multicolumn{6}{|c|}{ Gaza $(n=1931)$} & \multirow[b]{2}{*}{$P 0^{*}$} \\
\hline & 6th & 8th & 10th & 12th & Total & $P 1^{*}$ & 6th & 8th & 10th & 12th & Total & $P 2^{*}$ & \\
\hline Fruit (daily: once or more per day) & 36 & 27 & 28 & 24 & 29 & $<0.001$ & 30 & 28 & 21 & 24 & 25 & 0.009 & 0.006 \\
\hline er day) & 41 & 37 & 38 & 42 & 40 & 0.284 & 44 & 47 & 46 & 44 & 45 & & $<0.001$ \\
\hline ore per day) & 36 & 30 & 31 & 30 & 32 & 0.056 & 26 & 26 & 25 & 27 & 26 & 0.754 & $<0.00$ \\
\hline more per day) & 29 & 26 & 34 & 33 & 30 & 0.015 & 17 & 21 & 20 & 20 & 20 & 0.452 & $<0.00$ \\
\hline per day) & 34 & 28 & 21 & 18 & 26 & $<0.001$ & 28 & 28 & 23 & 20 & 24 & 0.0 & 0.192 \\
\hline ce or more per day) & 23 & 19 & 19 & 17 & 20 & 0.114 & 16 & 15 & 9 & 14 & 13 & 0.017 & $<0.001$ \\
\hline Breakfast during schooldays ( $\geq 4$ days a week) & 68 & 52 & 54 & 47 & 56 & $<0.001$ & 65 & 49 & 46 & 51 & 52 & $<0.001$ & 0.007 \\
\hline lieters) & 6 & 9 & 6 & 6 & 7 & 0.168 & 17 & 10 & 9 & 4 & 9 & $<0.001$ & 0.001 \\
\hline ctivity ( $\geq 5$ days a week) & 43 & 24 & 23 & 12 & 27 & $<0.001$ & 32 & 15 & 13 & 10 & 16 & $<0.001$ & $<0.001$ \\
\hline $4 \mathrm{~h}$ a day) & 30 & 29 & 31 & 26 & 29 & 0.363 & 30 & 22 & 24 & 28 & 26 & 0.035 & 0.017 \\
\hline Homework ( $\geq 4 \mathrm{~h}$ a day) & 6 & 6 & 5 & 32 & 11 & $<0.001$ & 23 & 13 & 11 & 18 & 16 & $<0.001$ & $<0.001$ \\
\hline Using computer & 33 & 40 & 40 & 32 & 36 & 0.006 & 28 & 38 & 36 & 39 & 36 & 0.009 & 0.909 \\
\hline
\end{tabular}

HBSC - Health Behaviour in School-aged Children.

${ }^{*}$ A significant difference in grades among boys by $\chi^{2}$ test. $P 1-P$-value between grades among boys in the West Bank; $P 2-P$-value between grades among boys in Gaza; $P O-P$-value between boys in the West Bank and Gaza. 
Table 4 Description (\%) of food intake and physical activity variables of girls by region and grades $6,8,10$ and 12 , and significance of the difference, Palestine, HBSC, 2004

\begin{tabular}{|c|c|c|c|c|c|c|c|c|c|c|c|c|c|}
\hline & \multicolumn{6}{|c|}{ West Bank $(n=2348)$} & \multicolumn{6}{|c|}{ Gaza $(n=2224)$} & \multirow[b]{2}{*}{$P 0^{*}$} \\
\hline & 6th & 8th & 10th & 12th & Total & $P 1^{*}$ & 6th & 8th & 10th & 12th & Total & $P 2^{*}$ & \\
\hline Fruit (daily: once or more per day) & 40 & 42 & 35 & 33 & 38 & 0.003 & 32 & 30 & 30 & 31 & 31 & 0.916 & $<0.00$ \\
\hline Vegetables (daily: once or more per day) & 48 & 47 & 47 & 48 & 47 & 0.978 & 46 & 50 & 51 & 49 & 49 & 0.521 & 0.3 \\
\hline Sweets (daily: once or more per day) & 49 & 45 & 45 & 46 & 46 & 0.503 & 50 & 29 & 30 & 32 & 36 & $<0.001$ & $<0.0$ \\
\hline Soft drinks (daily: once or more per day) & 33 & 30 & 24 & 26 & 29 & 0.005 & 15 & 14 & 14 & 15 & 15 & 0.929 & $<0.0$ \\
\hline Milk (daily: once or more per day) & 26 & 19 & 14 & 15 & 19 & $<0.001$ & 26 & 21 & 17 & 21 & 21 & 0.003 & 0.0 \\
\hline once or more per day) & 26 & 20 & 15 & 15 & 19 & $<0.001$ & 12 & 8 & 11 & 10 & 10 & 0.193 & $<0.00$ \\
\hline Breakfast during schooldays ( $\geq 4$ days a week) & 64 & 40 & 39 & 40 & 56 & $<0.001$ & 65 & 47 & 50 & 41 & 52 & $<0.001$ & $<0.00$ \\
\hline On diet (dieters) & 9 & 9 & 8 & 6 & 8 & 0.255 & 4 & 10 & 7 & 8 & 7 & 0.002 & 0.31 \\
\hline Physical activity ( $\geq 5$ days a week) & 43 & 21 & 17 & 14 & 24 & $<0.001$ & 13 & 11 & 13 & 6 & 11 & $<0.001$ & $<0.00$ \\
\hline TV viewing ( $\geq 4 \mathrm{~h}$ a day) & 30 & 41 & 41 & 26 & 35 & $<0.001$ & 14 & 24 & 31 & 27 & 24 & $<0.001$ & $<0.00$ \\
\hline Homework ( $\geq 4 \mathrm{~h}$ a day) & 18 & 17 & 20 & 46 & 24 & $<0.001$ & 10 & 20 & 22 & 31 & 20 & $<0.001$ & 0.003 \\
\hline Using computer & 30 & 31 & 23 & 17 & 26 & $<0.001$ & 15 & 20 & 22 & 19 & 19 & 0.028 & $<0.001$ \\
\hline
\end{tabular}

HBSC - Health Behaviour in School-aged Children.

${ }^{*}$ A significant difference in grades among girls by $x^{2}$ test. $P 1-P$-value between grades among girls in the West Bank; $P 2-P$-value between grades among girls in Gaza; $P 0$ - $P$-value between girls in the West Bank and Gaza.

About one-third (32\%) of the West Bank boys in grade 12 were doing homework $\geq 4 \mathrm{~h}$ a day in comparison with only $5-6 \%$ in other grades $(P<0.001)$. In contrast, the highest percentage (23\%) among boys of Gaza was found in grade 6 (Tables 3 and 4).

\section{Effects of parents' level of education}

Table 5 summarises the results of logistic regression analyses. Consumption of fruit and milk was positively associated with the level of education of both parents, while consumption of meat, chicken and soft drinks was positively associated with only the mother's level of education. In addition, taking breakfast on schooldays was positively associated with only the father's level of education. Parents' level of education has no effect on vegetable consumption and dieting status of children. Physical activity and TV viewing were positively associated with mother's level of education only $(P<0.01)$, while computer use was positively associated with both parents' level of education. Additionally, doing homework was positively associated with only the father's level of education.

\section{Discussion}

Adolescents of the West Bank consume more fruit, sweets, soft drinks, meat and chicken than adolescents in Gaza. This could be related to the geographical location of the Gaza Strip, which is a highly populated area and thus poverty may result in lack of accessibility and availability of some kinds of foods that are not locally grown or produced $^{14,16,17}$. In addition, people in the West Bank to some extent are wealthier and many have adopted a more Westernised lifestyle. A study about food consumption patterns among adults of the West Bank population indicated that the consumption of typical modern sugarrich foods, such as juices, soft drinks, biscuits and candies, has increased in most households during the last few years $^{18}$.

Table 5 Odds ratios of mother's/father's educational level in the logistic regression analysis with food consumption and physical activity patterns controlling for region

\begin{tabular}{lrrrr}
\hline & \multicolumn{1}{c}{$\begin{array}{c}\text { Mother's education } \\
\text { OR }^{*}(95 \% \mathrm{CI}), P \text {-value }\end{array}$} & \multicolumn{2}{c}{$\begin{array}{c}\text { Father's education } \\
\text { OR* }(95 \% \mathrm{Cl}), P \text {-value }\end{array}$} \\
\hline Fruit (daily: once or more per day) & $1.35(1.19-1.53)$ & $<0.001$ & $1.40(1.26-1.56)$ & $<0.001$ \\
Vegetables (daily: once or more per day) & $1.10(0.98-1.24)$ & 0.121 & $1.09(0.99-1.21)$ & 0.085 \\
Sweets (daily: once or more per day) & $1.15(1.01-1.30)$ & 0.029 & $1.09(0.98-1.21)$ & 0.117 \\
Soft drinks (high: once or more per day) & $1.28(1.11-1.48)$ & 0.001 & $1.10(0.97-1.24)$ & 0.128 \\
Milk (daily: once or more per day) & $1.30(1.13-1.49)$ & $<0.001$ & $1.21(1.07-1.37)$ & 0.002 \\
Meat and chicken (daily: once or more per day) & $1.68(1.44-1.97)$ & $<0.001$ & $0.98(0.85-1.12)$ & 0.734 \\
Breakfast during schooldays ( $\geq 4$ days a week) & $1.10(0.98-1.24)$ & 0.117 & $1.19(1.08-1.32)$ & 0.001 \\
On diet (dieters) & $1.20(0.98-1.49)$ & 0.085 & $1.03(0.86-1.24)$ & 0.747 \\
Physical activity ( $\geq 5$ days a week) & $1.26(1.09-1.46)$ & 0.002 & $1.02(0.90-1.16)$ & 0.769 \\
TV viewing ( $\geq 4$ h a day) & $1.25(1.10-1.42)$ & 0.001 & $1.02(0.91-1.14)$ & 0.702 \\
Homework $(\geq 4 \mathrm{~h}$ a day) & $1.09(0.94-1.26)$ & 0.262 & $1.22(1.07-1.38)$ & 0.002 \\
Using computer & $1.77(1.56-2.01)$ & $<0.001$ & $1.52(1.36-1.69)$ & $<0.001$ \\
\end{tabular}

$\mathrm{OR}$ - odds ratio; $\mathrm{Cl}$ - confidence interval.

${ }^{*}$ Reference category: low education. 
This study found that adolescents of the West Bank were doing more physical activity than adolescents of Gaza. Also, in the West Bank, girls watch TV more than boys, while no gender difference was found in Gaza in terms of watching TV. In the Gaza Strip, overcrowding and lack of sport centres because of the limited geographical area may result in the lower percentages of daily physical activity among adolescents. Consequently, boys in Gaza engage in watching TV or doing homework, while boys in the West Bank engage in sports activities outside their homes. The majority of people living in Gaza are refugees of 1948 and, because of overcrowding and lack of space, boys do their best in studying and doing homework in order to secure a better future with a higher income ${ }^{19}$.

\section{Gender differences}

Generally, girls are more likely to report healthier food choices, with a higher consumption of fruit and vegetables $^{20-22}$. In this study, girls reported consuming more fruit, vegetables and sweets, and less soft drinks and milk than boys. These findings are consistent with findings from the international dataset in which girls consume more fruits $^{23,24}$, vegetables $^{23}$ and less soft drinks than boys ${ }^{23,24}$.

Furthermore, this study found that boys are more physically active than girls in both regions. These findings are consistent with findings from other studies in which boys reported engaging in regular sports activities more than girls ${ }^{25,26}$. In Palestine as in other Arab countries, sports are to some extent not culturally acceptable among women, while boys are encouraged by their families and their social environment to play sports and be physically active.

\section{Grade/age differences}

Several age differences were found in boys of both regions. This study found that the proportion of boys who consume milk and fruit daily decreases with age. These finding are consistent with the HBSC studies from other countries where the proportion of adolescents who eat fruit every day decreases with age ${ }^{23}$. In addition, parents have more influence over the diets of their younger children, resulting in more healthy food intake.

Adolescents in both regions reported less physical activity with increasing age. Girls are less active than boys at all ages and tend to exercise less with increasing age $^{15,26,27}$. The international HBSC report indicated that more girls than boys reported dieting, and this difference increased significantly with age ${ }^{28}$. Although there is no logical explanation, an interesting finding in this study is that boys in Gaza were on a diet or doing something else to lose weight more than boys in the West Bank at the time when the survey was conducted. The highest percentage was found among boys in grade 6 in Gaza. This finding merits further investigation.

Finally, adolescents in both West Bank and Gaza in grade 12 spent more time doing homework and less time using a computer and watching TV. The highest percentage of students reporting doing homework was found among girls in grade 12 in the West Bank. In Palestine, students in the 12th grade, the last year of secondary school, take crucial final academic exams at the end of the year - their scores on these exams determine whether or not they will go on to university level study.

\section{Effects of parents' level of education}

Several studies have shown that the family socioeconomic status ${ }^{24,29-31}$ and the educational level of the mother $^{29,30}$ influence the food intake and the physical (in)activity of children. This study found that the level of education of both parents has a positive effect on fruit and milk consumption and that only the mothers' level of education has an effect on adolescents' meat, chicken and soft drink consumption. In contrast, consumption of vegetables was not affected by parents' level of education. Moreover, physical activity and TV viewing were positively affected by the mothers' level of education, while computer use was positively affected by both parent's level of education. Doing homework was positively affected by only the fathers' level of education. In Palestine, most vegetables are available and accessible at relatively cheap prices for most people. Mothers with higher education and families with a high standard of living have more access to expensive foods such as fruits, soft drinks, meat and chicken, and more leisure time to spend on physical activity, watching TV and using computers than less educated mothers and families with a low standard of living.

\section{Limitations}

One of the major limitations of this study was utilising selfreported responses from schoolchildren, which raises potential threats to reliability and validity. The study was also limited by its cross-sectional nature and subsequent inability to address questions of causality. The HBSC questionnaire has, on the other hand, been used extensively in many countries. We therefore believe that it captures a picture at a moment in time relatively well. The large sample size also ensures that deviations from the mean are counterbalanced.

\section{Conclusion}

This study revealed that there are problems with Palestinian adolescents' behaviour in relation to eating, dieting and physical activity. Parents play a direct role in children's eating and physical activity patterns. Although this is only the first time dietary practices and physical activity of Palestinian adolescents has been studied, the results indicate that policies need to be developed, implemented and evaluated to safeguard healthy eating habits and physical activity. More detailed studies are needed with elaborated instruments about food habits and physical 
activity of adolescents. Interventions aimed at improving adolescents' food habits and physical activity patterns targeting both parents and schools are also needed.

\section{Acknowledgements}

Sources of funding: This survey was supported by grants from the USAID MERC programme, grant number TAMOU-00-M20-051. The Belgium Technical Cooperation (BTC) sponsored the first author's doctorate study.

Conflict of interest declaration: All authors declare that they have no competing interests.

Authorship responsibilities: H.A., Z.A., C.V. and L.M. contributed to the conception, design, analysis and interpretation of data, drafting the manuscript and have given apporval of the final version for publication. Z.A. and H.A. contributed to the Palestinian HBSC data collection. P.K. contributed to interpretation of the data, commenting on the manuscript and has given approval of the final version for publication.

Acknowledgements: Data collection was conducted in cooperation with the Palestinian Ministry of Education and Al Quds University. The authors thank the Ministry of Education for their assistance in the data collection procedure and BTC for sponsorship. Our gratitude also goes to Mr Radwan Qasrawi for his efforts in monitoring the process of data entry and cleaning, and to Ms Ellen Coats for her contribution in editing the final version of the paper.

\section{References}

1 Yannakoulia M, Karayiannis D, Terzidou M, Kokkevi A, Sidoossis LS. Nutrition-related habits of Greek adolescents. European Journal of Clinical Nutrition 2004; 58: 580-6.

2 Saoirse NG, Geraldine N, Cecily K, Sharon F. Dieting patterns and related lifestyles of school-aged children in the Republic of Ireland. Public Health Nutrition 2002; 5: 457-62.

3 Jimenez-Cruz A, Bacardi-Gascon M, Jones EG. Consumption of fruits, vegetables, soft drinks, and high-fat-containing snacks among Mexican children on the Mexico-US border. Archives of Medical Research 2002; 33: 74-80.

4 Gaziano JM, Manson JE, Branch LG, Colditz GA, Willett WC, Buring JB. A prospective study of consumption of carotenoids in fruits and vegetables and decreased cardiovascular mortality in the elderly. Annals of Epidemiology 1995; 5: 255-60.

5 Shepherd R, Dennison CM. Influences on adolescent food choices. Proceedings of the Nutrition Society 1996; 55: 345-57.

6 Tur JA, Puig MS, Benito E, Pons A. Associations between sociodemographic and lifestyle factors and dietary quality among adolescents in Palma de Mallorca. Nutrition 2004; 20: 502-8.

7 Ahmed F, Zareen M, Khan MR, Banu CP, Haq MN, Jackson AA. Dietary pattern, nutrient intake and growth of adolescent school girls in urban Bangladesh. Public Health Nutrition 1998; 1: 83-92.

8 Giskes K, Turrell G, Patterson C, Newman B. Socioeconomic differences in fruit and vegetable consumption among Australian adolescents and adults. Public Health Nutrition 2002; 5: 663-9.
9 World Health Organization Cross-National Study. Health Behaviour in School-aged Children. Research Protocol for 2001/02 Survey [online]. Available at http://www.hbsc.org

10 Palestinian Central Bureau of Statistics (PCBS). Palestinian Youth: Facts and Figures. Ramllah: PCBS, 2001.

11 Abdeen Z, Greenough G, Qasrawi R, Dandie B. Nutritional Assessment of the West Bank and Gaza Strip. Jerusalem: Jerusalem Press, 2003.

12 Abdeen Z, Greenough G, Shaheen M, Tayback M. Nutritional Assessment of the West Bank and Gaza Strip. Jerusalem: Jerusalem Press, 2002.

13 Abdeen Z, Qleibo M, Dkeidek S, Qasrawi R, Bargouthy F. First Palestinian National Health and Nutritional Survey. Public Health Reviews 2000; 28: 27-30.

14 World Health Organization, UNICEF, Palestinian Ministry of Health. The State of Nutrition, West Bank and Gaza Strip: a comprehensive review of nutrition situation of West Bank and Gaza [online], 2005. Available at http://www.moh.gov. ps/pdffiles/State\%20of\%20Nutrition\%20-\%20June\%202005\% 20_2_.pdf.

15 World Health Organization (WHO). The Health Behaviour of School Children in Northern Ireland. A Report on the 1997/98 Survey. A WHO Collaborative Study. Geneva: WHO, 2000.

16 World Bank. Poverty in the West Bank and Gaza. Report No. 22312-GZ. Washington, DC: Middle East and North Africa Region, World Bank, 2001.

17 United Nations, Standing Committee on Nutrition Occupied Palestinian Territories [online], 2003. Available at http:// www.unsystem.org/scn/archives/rnis43/middleeast.htm

18 Stene LCM, Gicaman R, Abdul-Rahim H, Husseini A, Norum KR, Holomboe-Ottesen G. Food consumption patterns in a Palestinain West Bank population. European Journal of Clinical Nutrition 1999; 53: 953-8.

19 Arafat C. A psychosocial assessment of Palestinian Children. Save the Children Report [online], 2003. Available at http:// www.caresaveupdate.org/FinalCPSPAssessmentEnglish.pdf

20 Wardle J, Haase AM, Steptoe A, Nillapun M, Jonwutiwes K, Bellisle F. Gender differences in food choice: the contribution of health beliefs and dieting. Annals of Behavioral Medicine 2004; 27: 107-16.

21 Westenhoefer J. Age and gender dependent profile of food choice. Forum of Nutrition 2005; 57: 44-51.

22 Robbins LB, Pender NJ, Kazanis AS. Barriers to physical activity perceived by adolescent girls. Journal of Midwifery $\mathcal{E}$ Women's Health 2003; 48: 206-12.

23 Vereecken C, Ojala K, Delgrande-Jordan M. Eating habits. In: Currie C, Roberts C, Morgan A, Smith R, Settertobulte W, Samdal $\mathrm{O}$, et al., eds. Young People's Healthy in Context. Health Behaviour in School-aged Children (HBSC) Study: International Report from the 2001/2002 Survey. WHO Policy Series: Health Policy for Children and Adolescents Issue 4. Copenhagen: World Health Organization Regional Office for Europe, 2004; 110-9.

24 Vereecken C, Inchley J, Subramanian S, Hublet A, Maes L. The relative influence of individual and contextual socioeconomic status on consumption of fruit and soft drinks among adolescents in Europe. European Journal of Public Health 2005; 15: 224-32.

25 Cavadini C, Decarli B, Grin J, Narring F, Michaud PA. Food habits and sport activity during adolescence: differences between athletic and non-athletic teenagers in Switzerland. European Journal of Clinical Nutrition 2000; 54: 16-20.

26 Roberts C, Tynjala J, Komkov A. Physical activity. In: Currie C, Roberts C, Morgan A, Smith R, Settertobulte W, Samdal O, et al., eds. Young People's Health in Context. Health Behaviour in School-aged Children (HBSC) Study: International Report from the 2001/2002 Survey. WHO Policy Series: Health Policy for Children and Adolescents Issue 4. 
Copenhagen: World Health Organization Regional Office for Europe, 2004; 90-7.

27 Davis MJ. New Mexico 2000 Middle school youth risk behavior survey, report of state results [online], 2000. Available at http://www.healthierschools.org/NM00MSYRBSfinalreport.pdf

28 Mulvihill C, Nemeth A, Vereecken C. Body image, weight control and body weight. In: Currie C, Roberts C, Morgan A, Smith R, Settertobulte W, Samdal O, et al., eds. Young People's Health in Context. Health Behaviour in School-aged Children (HBSC) Study: International Report from the 2001/2002 Survey. WHO Policy Series: Health Policy for Children and Adolescents Issue 4. Copenhagen: World Health Organization Regional Office for Europe, 2004; 120-9.
29 Antal M, Nagy K, Biro L, Greiner E, Regoly-Merei A, Domonkos A, et al. Cross-sectional survey on the nutritional and life-style habits of secondary school students in Hungary. Orvosi hetilap 2003; 144: 1631-6.

30 Serra Majem L, Ribas Barba L, Perez Rodrigo C, Roman Vinas B, Aranceta Bartrina J. Dietary habits and food consumption in Spanish children and adolescents (19982000): socioeconomic and demographic factors. Medicina Clínica 2003; 121: 126-31.

31 Vereecken C, Todd J, Roberts C, Mulvihill C, Maes L. Television viewing behaviour and associations with food habits in different countries. Public Health Nutrition 2006; 9: $244-50$. 